\title{
Students’ Proof Schemes for Disproving Mathematical Proposition
}

\author{
Mochammad Amirudin, Yusuf Fuad and Pradnyo Wijayanti \\ Program Pascasarjana, Department of Mathematics, Universitas Negeri Surabaya, Ketintang, Surabaya 60231, East \\ Java, Indonesia \\ mochammadamirudin16070785013@mhs.unesa.ac.id
}

\begin{abstract}
Proof and proving play an important role for students in justifying the validity of mathematical propositions. This qualitative research was concerned to assess students' proof schemes for disproving mathematics propositions. The sample was $11^{\text {th }}$ grade students of SMAN 1 Surabaya. All students had to answer two tests, namely the mathematics ability test and the proof-by-counterexample test. Three volunteer students (girls), with high mathematics ability and high score in proof-bycounterexample test, were selected as research subjects. For investigating the students' proof schemes, semi-structured interview was conducted to three subjects. The data quality of proof schemes was categorized in 6 levels of proof-bycounterexample criteria. The results revealed that all students were able to prove the mathematics proposition and there were still differences each other. One student was able to demonstrate the falseness of the mathematical proposition by giving a general counterexample with mathematics symbols, so the student was in highest level, $5^{\text {th }}$ level. Meanwhile, others were in the $4^{\text {th }}$ levels because they were able to state that the falseness of the mathematics proposition by a specific counterexample. They couldn't change the specific counterexample to become a general counterexample with mathematics symbols. This finding suggests, the need for further research regarding to gender.
\end{abstract}

Keywords- Proof, Proof Schemes, Disproving, Counterexample.

\section{INTRODUCTION}

Proving and disproving play an important role for students in justifying the validity of mathematical propositions. They can demonstrate whether and why the proposition is true or false. In mathematics, proving and disproving are inextricably linked given the role each plays in establishing mathematical knowledge [1-3]. In other hand, counterexample had relation with disproving activity. Counterexample can illustrate whether and why the proposition is false. If single counterexample was exist, then the proposition is false correctly [4,5]. Thus, proving and counterexample are two kinds of mathematics term that running together and demonstrate whether and why the proposition is true or false.

Proving consist of constructing proof and validating proof $[3,6,7,8]$. Students' proof construction represents how students construct a proof. Students' proof construction is thinking schemes in arranging logical arguments to demonstrate trueness or falseness of statements. The manner of students in constructing a proof refers to proof schemes.

The proof scheme is a characteristic of proof as the result of a mental activities of proving. The students' proof schemes represent how they construct the proof, validating the proof, and explain whether and why a mathematical statement is true or false $[9,10]$. The student proof scheme is cognitive schemes that is underlying in organizing and interpreting information about students' proof construction [11-13].

The study of student proof schemes for disproving mathematical propositions is limit. Even though, the study of student proof schemes that involving counterexample and false propositions provides a great opportunity in understanding the construction of student proofs. The classification of the student proof schemes is one potential way to inform teachers / educators about the students' ability to refuse a mathematical proposition [3,6,14]. The classification of the students' proof schemes on mathematical propositions is needed to more understanding how students use examples, conclusions, and counterexamples while they develop more deductive reasoning.

Therefore, this study aimed to investigate and describe students' proof schemes for disproving mathematical proposition. The students' proof schemes are analyzed based on quality of proof that they constructed and the knowledge they have in proving. Then they are analyzed based on levels of proof schemes [3]. This qualitative research used the test of proof-by-counterexample and interview.

\section{METHOD}

This qualitative research concerned to assess students' proof construction schemes in disproving mathematics propositions. The sample was the $11^{\text {th }}$ grade students of SMAN 1 Surabaya. 38 (13 males \& 25 females) students had to answer two tests, both mathematics ability test and proofby-counterexample test. Four volunteer students (girls), with 
high mathematics ability and high score in proof-bycounterexample test, were selected as research subjects. A semi-structured interview was individually conducted to every subjects. Each student was interviewed during 20 minutes. The data of proof schemes was categorized in six levels of proof-by-counterexample criteria.

This student proof scheme is analyzed based on their knowledge of proof construction and proof validation. To identify the levels of students' proof schemes are used descriptor of the proof scheme. This proof scheme descriptors are modified from the Lee's proof scheme descriptors [3]. The Descriptors of students' proof schemes for disproving mathematical propositions that is used in this study explain in Table 1.

TABLE I. DESCRIPTORS OF STUDENTS' PROOF SCHEMES FOR DISPROVING MATHEMATICAL PROPOSITION

Table was adopted from [3]

\begin{tabular}{|c|c|c|}
\hline Level & Characteristics & Description of students' proofs \\
\hline 0 & $\begin{array}{l}\text { Irrelevant or } \\
\text { minimal } \\
\text { engagement in } \\
\text { inferences }\end{array}$ & $\begin{array}{l}\text { - Do not know how to prove or appeal to } \\
\text { conviction in external knowledge } \\
\text { sources } \\
\text { - Unable to relate the antecedent with the } \\
\text { consequent with examples }\end{array}$ \\
\hline 1 & $\begin{array}{l}\text { Novice use of } \\
\text { examples for } \\
\text { reasoning } \\
\begin{array}{l}\text { logical } \\
\text { reasoning }\end{array}\end{array}$ & $\begin{array}{l}\text { - Conclude the implication is false (or } \\
\text { true incorrectly) using an incorrect } \\
\text { example or counterexample (or one or } \\
\text { more correct examples) } \\
\text { - Falsify the implication "if P then Q" } \\
\text { through erroneous logical reasoning, } \\
\text { e.g., "if not P then not Q" }\end{array}$ \\
\hline 2 & $\begin{array}{l}\text { Strategic use of } \\
\text { examples for } \\
\text { reasoning }\end{array}$ & $\begin{array}{l}\text { - Generate examples based on random or } \\
\text { case-based sampling, or extreme cases } \\
\text { - Uses mathematical properties inferred } \\
\text { from generated examples to make } \\
\text { conclusions }\end{array}$ \\
\hline 3 & $\begin{array}{l}\text { Deductive } \\
\text { inferences with } \\
\text { major flaws in } \\
\text { logical } \\
\text { coherence and } \\
\text { validity }\end{array}$ & $\begin{array}{l}\text { - Deduce the implication to be true } \\
\text { incorrectly for some cases of the } \\
\text { antecedent but omit other falsifying } \\
\text { cases due to misconceptions }\end{array}$ \\
\hline 4 & $\begin{array}{l}\text { Construction of } \\
\text { Proof-by- } \\
\text { counterexample }\end{array}$ & $\begin{array}{l}\text { - Deduce the implication to be false by } \\
\text { constructing one or few specific } \\
\text { counterexamples }\end{array}$ \\
\hline 5 & $\begin{array}{l}\text { Construction of } \\
\text { Proof-by- } \\
\text { general- } \\
\text { counterexample }\end{array}$ & $\begin{array}{l}\text { - Deduce the implication to be false by } \\
\text { constructing a general set of } \\
\text { counterexamples and identifying the } \\
\text { property of the set that falsifies the } \\
\text { implication }\end{array}$ \\
\hline
\end{tabular}

\section{RESULTS AND DISCUSSION}

A total of 38 students have done on the mathematics ability test and 76 students' proof construction (38 students; each student doing on 2 types of proof-by-counterexample test) have been analyzed. I present the finding of student's proof-by-counterexample schemes. 38 of $11^{\text {th }}$ grade students answer the proof-by-counterexample test and the results as Table 2.
TABLE II. FREQUENCY DISTRIBUTION OF STUDENT'S TWO TYPES TEST SCORE

\begin{tabular}{|c|c|c|c|c|c|c|}
\hline \multirow{2}{*}{ Gender } & \multicolumn{3}{|c|}{ Mathematics Ability } & \multicolumn{3}{c|}{ Proof-by-counterexample Score } \\
\cline { 2 - 7 } & High & Middle & Low & $\begin{array}{c}0 \leq \mathrm{ss}< \\
60\end{array}$ & $\begin{array}{c}60 \leq \mathrm{ss}< \\
80\end{array}$ & ss $\geq 80$ \\
\hline Boys & 4 & 6 & 3 & 5 & 6 & 2 \\
\hline Girls & 14 & 7 & 4 & 8 & 14 & 3 \\
\hline
\end{tabular}

Based on the results, students who have the highest score of each type of test and have the same gender are selected, so there were 3 (girls) students who are subsequently interviewed to know the students thinking in constructing the proof.

The four students (Risa, Sasa, and Sandra; disguised) do two questions of proof-by-counterexample. The results shown that two of them, are at fourth level, while the other at the highest level, fifth level. Here is the test, answers, and interviews of selected students.

1. If $n$ is any natural number, then $n^{2}>n$ is true. Is the proposition true or false?

2. If you add any consecutive whole numbers, then the sum will be divisible by many numbers you added up. Is the proposition true or false?

Figure 1: The Instruments of Proof-by-counterexample

A. Risa Proof Schemes

Risa's solution in problem 1 and 2 showed in Figure 2 and Figure 3.

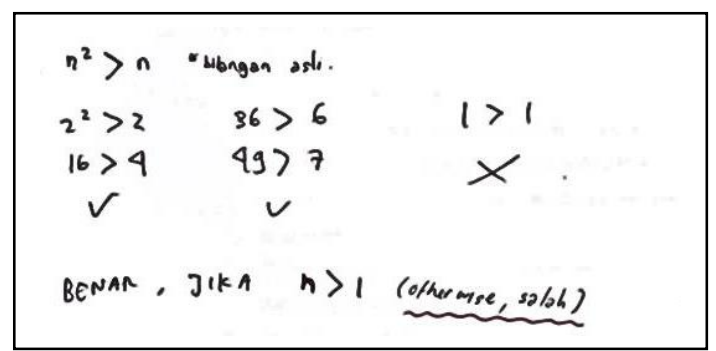

Figure 2: Risa's Solution in Problem 1

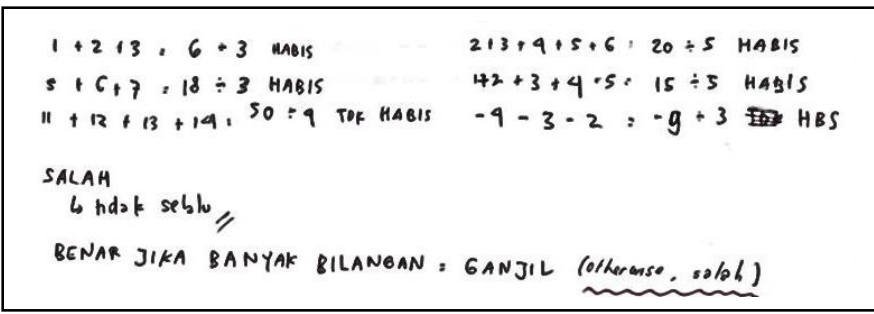

Figure 3: Risa's Solution in Problem 2

Risa considered problem 1 a simple because it is easy to understand. Risa started the construction of proof by experimenting with several random numbers. The numbers that she chosen were $2,6,7$. Then she substituted it into $n^{2}>n$, so that it was obtained $4>2,36>6$, and 
$49>7$. He argued that some of these numbers satisfied the proposition, so that in some cases used, at first it concludes tentatively that the proposition is true, as the following interview quotes.

Researcher : Why do you conclude that the proposition is true?

Risa : Because some numbers that I used is right. But not all natural number.

Risa constructed the proof again by adding one more number, which is 1 . Then she substituted it into $n^{2}>n$, so that $1>1$ was obtained. Risa considered that $1>1$ was a false statement as the following interview quotes.

Researcher : Why do you conclude that the proposition is false?

Risa $\quad$ : Because there is $1>1$. A number more than itself is nothing. So $1>1$ is false.

Risa showed one counterexample 1 thus causing the mathematical proposition to be false [1-4]. Risa concluded that

the proposition was true for $n>1$, and false when $n=1$. The conclusion was based on some specific example given.

In solving Problem 2, Risa constructed the proof by trying several numbers. Risa started it by adding 3 consecutive

whole numbers, $1+2+3=6$. Then she divided it by 3 (many consecutive whole numbers are added) so the result was divisible by 3 . She done the same thing to different numbers 5 times. Furthermore, Risa done the same thing with several other numbers but with many different consecutive whole numbers, which are four numbers. Risa added $11+12+13+14=50$, then she divided the result by 4 (many consecutive whole numbers are summed) so the result was not divisible by 4 . Risa concluded that the proposition was false when many consecutive whole numbers are summed was odd and the proposition was true when consecutive whole numbers are summed was even. This conclusion was based on specific examples that have been constructed.

Risa's proof construction on problems 1 and 2 indicated that the proposition was false based on a specific counterexample. Risa couldn't construct proof by using general mathematics symbols. The collection of random number samples were still classified in an inductive thinking $[6,11,14]$. It shown that Risa's proof scheme was at fourth level [3].

\section{B. Sasa's Solution}

Sasa's solution in problem 1 and 2 showed in Figure 4 and Figure 5.

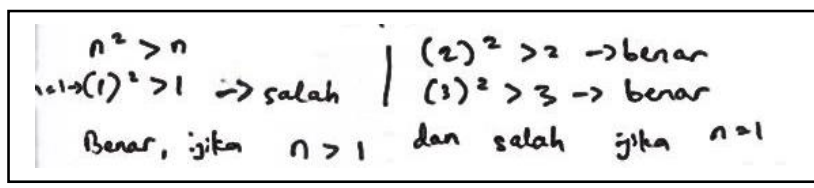

Figure 4: Sasa's Solution in Problem 1

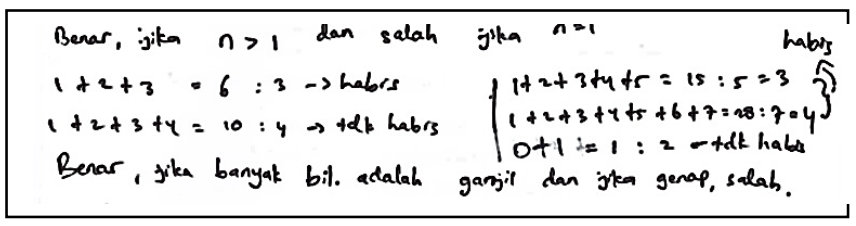

Figure 5: Sasa's Solution in Problem 2

In constructing the proof on Problem 1, Sasa constructed the proof by making specific examples. Sasa took several numbers of 1,2 , and 3 . Then she substituted it into the form $n^{2}>n$, so that $1>1,4>2$, and $9>3$ were obtained.

Sasa stated that $4>2$ and $9>3$ were correct statements.

Whereas $1>1$ was an incorrect statement. It appeared that the proof schemes belong to the inductive proof scheme that proving of some specific matter and then concluding it in general terms $[6,11,14]$. Based on the examples given, Sasa

concluded that $n^{2}>n, n$ the natural number, was false for $n=1$ and $n^{2}>n, n$ the natural number, was true for $n>1$

The construction of proof on question 2, Sasa also begin by making specific examples of whole numbers and some special cases as many numbers are summed up is 3 and 4 . The she started up with many whole numbers are summed is odd. Sasa summed three consecutive whole numbers

$1+2+3=6$, then she divided the result by 3 (many consecutive whole numbers are summed) so the result was divisible by 3 . Next, Sasa summed five consecutive whole

numbers i.e. $1+2+3+4+5=15$. Then the result was divided by 5 (many consecutive whole numbers are summed), so the result was divisible by 5 .

The same way was done, but with many different consecutive whole numbers. Sasa added four consecutive

whole numbers $1+2+3+4=10$, then she divided the result by 4 (many whole numbers are summed) and the result 
was not divisible by 4 . Next Sasa added two consecutive whole numbers, then the result was divided by 2 so the result was not divisible by 2 . Sasa concluded that the proposition was true when many consecutive whole numbers are summed was odd and the proposition was false when the summed number was even.

Sasa showed that 1 was a counterexample that could refuse mathematical proposition [1-4]. However, Sasa didn't understand the term counterexample as the following interview quotes.

Researcher : Do you know what counterexample is? Sasa : I don't know counterexample term.

The construction of proof done on Problem 2 did't use general examples. Sasa only used specific examples and based on specific cases. The collection of random number samples was still classified in an inductive thinking [6,12,14]. This shows that Sasa's proof scheme was at $5^{\text {th }}$ level [3].

\section{Sadra's Solution}

Sandra's solution in Problem 1 and 2 showed in Figure 6 and Figure 7.

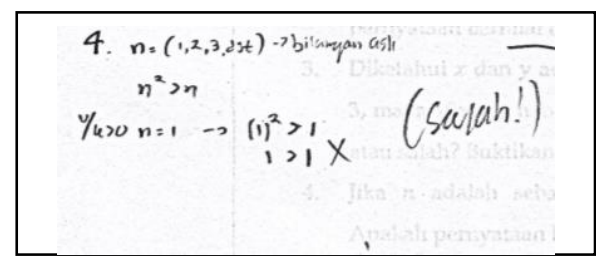

Figure 6: Sandra's Solution in Problem 1

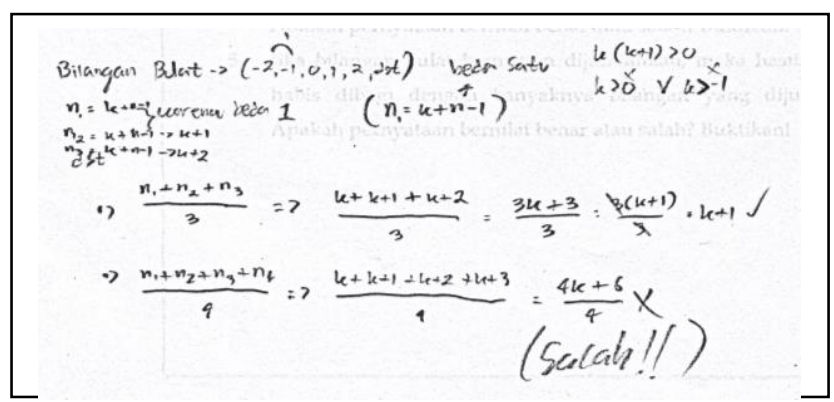

Figure 7: Sandra's Solution in Problem 2

In constructing the proof on Problem 1, Sandra began by taking a specific example of a natural number that was 1 . Then

she substituted it to $n^{2}>n$, so $1>1$ was obtained. Sandra

stated that $1>1$ was an incorrect statement. Based on this example, Sandra concluded that the proposition was false as the following interview quotes.

Researcher : why do you conclude that the proposition is false?
Sandra : because there is counterexample, that is 1.

Researcher : only 1 ?

Sandra : :yes

Researcher : you just have 1 counterexample, how can you conclude like that?

Sandra : One counterexample is enough for refusing the proposition, I think. Because one counterexample make the set of proposition be not satisfy.

Based on the interview above, Sandra knew what the counterexample was. She stated that one counterexample was enough to rejecting the proposition, so she said that the proposition was false. It was because there was a 1 number that results in a number that didn't satisfy in the set of numbers so the proposition became false [4, 5,13]. In constructing proof, Sandra used strong logical reasoning [3, $6]$.

Proof construction on Problem 2, Sandra constructed the proof using a general example and on a specific case. The cases are many consecutive whole numbers summed is odd and many consecutive whole numbers summed is even. Beside that, Sandra understood that consecutive whole number could

be expressed by $n,(n+1),(n+2),(n+1), \ldots$

Sandra constructed the proof with case I that many consecutive whole numbers summed is odd. Sandra added three consecutive whole numbers. She changed the consecutive whole number in general form

$n+(n+1)+(n+2)=3 n+3=3(n+1)$. Then she divided the result by 3 (many consecutive whole numbers are

summed) so the result was divisible by 3 because $3(n+1)$ is multiple of 3 . Then in case II (many consecutive number summed is even), Sandra summed four consecutive whole numbers. Sandra summed the consecutive whole numbers in the general form

$n+(n+1)+(n+2)+(n+3)=4 n+6=2(2 n+$ 3)

. Then she divided the result by 4 (many consecutive whole numbers) so the result was not divisible by 4 . Since there was 1 invalid case, Sandra concluded that the proposition was false. Sandra was guided that if there is one counterexample applicable to the proposition, then the proposition is false $[1,2,3]$.

The proof that is constructed by Sandra on Problem 1 and 2 indicated that Sandra concluded a false proposition based on a general counterexample. Beside that, Sandra constructed the proof by using mathematical symbols. Proof by using mathematics symbol could be belong to formal proof. The use of the general form of consecutive whole numbers indicated that Sandra had a high logical reasoning [3, 6, 14]. 
This showed that Sandra's proof scheme is at $5^{\text {th }}$ level [3], i.e. the highest level of proof schemes which concluded a mathematical proposition by using a general counterexample.

\section{CONCLUSION}

Based on the result of the study, we concluded that the students' proof scheme for disproving mathematical propositions is still low because most students were able to show counterexample specific and only one of 38 students in 11th grades school was able to demonstrate general counterexample by using mathematical symbol. Thus, there needs to increase proof-based learning so that students are able to improve logical reasoning and logical thinking as a provision to improve a higher thinking.

\section{ACKNOWLEDGEMENT}

This research reported here in was supported by SMAN 1 Surabaya, especially for 11th grade of IPA-2 class as samples, and Agustin Tika Maya as teacher in this class who helped the research.

\section{REFERENCES}

[1] Y. Ko and E. Knuth, 'Undergraduate Mathematics Majors' Writing Performance Producing Proofs and Counterexamples About Continuous Functions", Journal of Mathematical behavior, vol. 28, pp. 68-77, 2009.

[2] K. Komatsu, "Counter-examples for Refinement of Conjectures and Proofs in Primary School Mathematics", Journal of Mathematical behavior, vol. 29, pp. 1-10, 2010.
[3] K. Lee, "Students' Proof Schemes for Mathematical Proving and Disproving of Propositions", The Journal of Mathematical Behavior, vol. 41, pp. 26-44, 2016.

[4] D. Ley and P. A. Wesley, Linear Algebra and Its Applications, 2008.

[5] G. Chartrand, A. Polimeni, and P. Zhang, Mathematical proofs, Kanada: Aptara Inc. 2013.

[6] G. Harel and L. Sowder, "Toward comprehensive perspectives on the learning and teaching of proof. In F. K. Lester Jr. (Ed.), Second handbook of research on mathematics teaching and learning", vol. 2, pp. 805-842, 2007.

[7] L. Alcock and M. Inglis, "Doctoral Students' Use of Examples in Evaluating and Proving Conjectures", Educational Studies in Mathematics, vol. 69, no. 2, pp. 111- 129, 2008.

[8] A. Selden and J. Selden, "Mathematical and Non-Mathematical University Students ${ }^{\text {ee }}$ Proving Diffulties. Wiest L R \& Lamberg T (Eds)", Proceedings of the 33rd Annual Meeting of the North American Chapter of the International Group for the Psychology of Mathematics Education, 2011, pp. 675-683

[9] K. Weber and J. P. Mejia-Ramos, "Mathematics Majorse Belief About Proof Reading. International", Journal of Mathematical Education in Science and Technology, vol. 45, no. 1, pp. 89-103, 2014.

[10] K. Weber and J. P. Mejia-Ramos, "On Relative and Absolute Conviction in Mathematics", For the Learning of Mathematics, vol. 35, no. 2, pp. 15-21, 2015.

[11] D. Housman and M. Porter, "Proof Schemes and Learning Strategies of Above-Average Mathematics Students", Educational Studies in Mathematics, vol. 53, no. 2, pp. 139-158, 2003.

[12] D. Stylianou, N Chae, M. and Blanton, "Students' proof Schemes: A Closer Look at What Characterizes Students' Proof Conceptions", Proceedings of the 28th annual meeting of the North American Chapter of the International Group for the Psychology of Mathematics Education. Mérida, México: Universidad Pedagógica Nacional, 2006.

[13] I. Kanellos, Sedondary Students' Proof Schemes During The First Encounters with Formal Mathematical Reasoning: Appreciation, Fluency, and Readiness Thesis: University of East Anglia, 2014.

[14] M. Miyazaki M, "Levels of proof in lower secondary school mathematics", Educational Studies in Mathematics, vol. 41, no. 1, p. 47, 2000 . 